\title{
Genomic surveillance of Acinetobacter baumannii in the Philippines, 2013-2014
}

Jeremiah Chilam, ${ }^{a, \dagger}$ Silvia Argimón, b,, Marilyn T. Limas, ${ }^{a}$ Melissa L. Masim, ${ }^{a}$ June M. Gayeta, ${ }^{a}$ Marietta L. Lagrada, ${ }^{a}$ Agnettah M. Olorosa, ${ }^{a}$ Victoria Cohen, ${ }^{b}$ Lara T. Hernandez, ${ }^{a}$ Benjamin Jeffrey, ${ }^{b}$ Khalil Abudahab, ${ }^{b}$ Charmian M. Hufano, ${ }^{a}$ Sonia B. Sia, ${ }^{a}$ Matthew T.G. Holden, ${ }^{c}$ John Stelling, ${ }^{d}$ David M. Aanensene, ${ }^{e}$ and Celia C. Carlos ${ }^{a,}$ on behalf of the Philippines Antimicrobial Resistance Surveillance Program

Correspondence to David M. Aanensen and Celia Carlos (email: david.aanensen@bdi.ox.ac.uk and ccarlosphl@gmail.com)

Objective: Acinetobacter baumannii is an opportunistic nosocomial pathogen that has increasingly become resistant to carbapenems worldwide. In the Philippines, rates of carbapenem resistance and multidrug resistance are above $50 \%$. We undertook a genomic study of carbapenem-resistant $A$. baumannii in the Philippines to characterize the population diversity and antimicrobial resistance mechanisms.

Methods: We sequenced the whole genomes of $117 \mathrm{~A}$. baumannii isolates recovered by 16 hospitals in the Philippines between 2013 and 2014. From the genome sequences, we determined the multilocus sequence type, presence of acquired determinants of antimicrobial resistance and relatedness between isolates. We also compared the phenotypic and genotypic resistance results.

Results: Carbapenem resistance was mainly explained by acquisition of the class-D $\beta$-lactamase gene bla $a_{0 \times-23}$. The concordance between phenotypic and genotypic resistance to imipenem was $98.15 \%$, and it was $94.97 \%$ overall for the seven antibiotics analysed. Twenty-two different sequence types were identified, including 7 novel types. The population was dominated by the high-risk international clone 2 (i.e. clonal complex 92), in particular by ST195 and ST208 and their single locus variants. Using whole-genome sequencing, we identified local clusters representing potentially undetected nosocomial outbreaks, as well as multi-hospital clusters that indicated interhospital dissemination. Comparison with global genomes suggested that the establishment of carbapenem-resistant international clone 2 in the Philippines is likely the result of clonal expansion and geographical dissemination, and at least partly explained by inadequate hospital infection control and prevention.

Discussion: This is the first extensive genomic study of carbapenem-resistant $A$. baumannii in the Philippines, and it underscores the importance of hospital infection control and prevention measures to contain high-risk clones.

$\mathrm{H}$ ospital-acquired Acinetobacter baumannii infections are some of the most challenging to treat due to the bacterium's ability to acquire resistance to different groups of antimicrobials and to survive for long periods on dry surfaces, making eradication in health care facilities difficult once it has become endemic. ${ }^{1}$ A previous surveillance study in the Asia-Pacific area showed that Acinetobacter spp. was the organism most frequently isolated in ventilator-associated pneumonia, ${ }^{2}$ while in recent years the Philippines Antimicrobial Resistance Surveillance Program (ARSP) has consistently reported $A$. baumannii as the second and third most commonly isolated organism from, respectively, cerebrospinal fluid and respiratory specimens. ${ }^{3}$

During the past two decades, $A$. baumannii has become increasingly resistant to carbapenems worldwide, with resistance rates of $>40 \%$ reported across several countries in the Asia-Pacific area, which is the highest prevalence of carbapenem resistance among important nosocomial Gram-negative pathogens. ${ }^{4,5}$ This pattern is alsoobserved inthePhilippines, wheretheannual resistance rates for several antibiotics, including carbapenems,

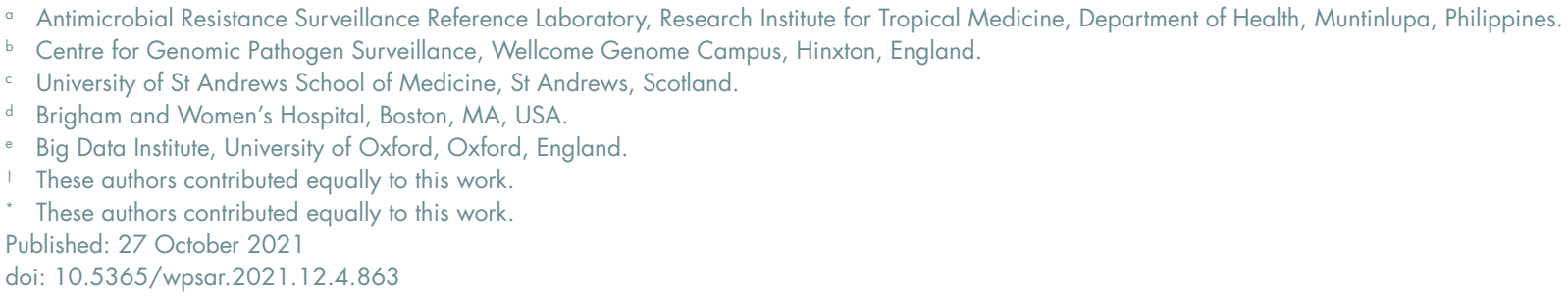


have been increasing, in 2017 reaching 56\% for meropenem and $57 \%$ for imipenem (Fig. 1A-C). In addition, the ARSP has reported rates of multidrug resistance of $63 \%$ for all isolates and $47 \%$ for blood isolates, with combined resistance to aminoglycosides, fluoroquinolones, carbapenems and ampicillin-sulbactam. ${ }^{3}$ Importantly, bacteraemia due to multidrug-resistant (MDR) A. baumannii has been shown to result in additional hospitalization and costs compared with bacteraemia due to non-MDR A. baumannii. ${ }^{6}$

Molecular typing methods have shown that clinical isolates of $A$. baumannii with an MDR phenotype belong mostly to two globally disseminated lineages: global clone (GC) 1 and GC2, also known as international clones (ICs) 1 and 2. Clonal complex 92 (CC92), corresponding to GC2, was the most prevalent in a previous study in nine Asian countries that included two isolates from the Philippines. $^{7}$

The ARSP has been conducting surveillance of drug-resistant $A$. baumannii using phenotypic detection methods for bacterial identification and antimicrobial susceptibility testing. Whole-genome sequencing (WGS) can provide information on antimicrobial resistance (AMR) and genotyping with a single assay and with additional resolution to aid outbreak investigations. ${ }^{8}$ Understanding the molecular epidemiology and AMR mechanisms of A. baumannii by monitoring the presence of international clones and the emergence of novel lineages in the Philippines can aid in the control of AMR. This report provides baseline data on the molecular epidemiology of $A$. baumannii in the Philippines, with a focus on the predominant circulating lineages and AMR mechanisms.

\section{METHODS}

\section{Bacterial isolates}

A total of $5254 \mathrm{~A}$. baumannii isolates were collected and tested for antimicrobial susceptibility by the ARSP's sentinel sites from January 2013 to December 2014. Isolates resistant to carbapenems were subsequently referred to the Antimicrobial Resistance Surveillance Reference Laboratory for confirmation. Out of the 445 carbapenem-resistant $A$. baumannii isolates referred (155 in 2013 and 290 in 2014), 117 from 16 sentinel sites were selected for WGS according to the following criteria (previously described in detail): ${ }^{9}$ (i) isolate was referred to the Reference Laboratory during 2013-2014; (ii) complete antimicrobial susceptibility data were available (i.e. a resistance profile); (iii) the overall prevalence of the resistance profile was in the ARSP database (including both referred and non-referred isolates); (iv) geographical representation of the different sentinel sites was present; (v) invasive isolates (i.e. from blood or cerebrospinal, joint, pleural or pericardial fluids) were selected when both invasive and non-invasive isolates were available for a combination of resistance profile, sentinel site and year of collection (Table 1). We utilized a proxy definition for "infection origin" whereby patients' isolates collected on either of the first 2 days of hospitalization were categorized as from communityacquired infections, while isolates collected on hospital day 3 or later were categorized as from hospital-acquired infections.

\section{Antimicrobial susceptibility testing}

All $A$. baumannii isolates included in this study were tested for antimicrobial susceptibility to nine antibiotics representing six different classes: ceftazidime (CAZ), ceftriaxone (CRO), imipenem (IPM), ampicillinsulbactam (SAM), piperacillin-tazobactam (TZP), gentamicin (GEN), amikacin (AMK), ciprofloxacin (CIP) and sulfamethoxazole-trimethoprim (SXT) (Table 1). Antimicrobial susceptibility was determined at the Reference Laboratory using one or a combination of the following methods: Kirby-Bauer disk diffusion; a gradient method, such as the E-Test (bioMérieux; Marcyl'Étoile, France); or the Vitek 2 Compact automated system (bioMérieux; Marcy-l'Étoile, France). The zone of inhibition and minimum inhibitory concentration obtained were interpreted according to the twentysixth edition of the Clinical and Laboratory Standards Institute guidelines ${ }^{10}$ to determine the resistance profile of the isolates as a list of antimicrobials to which the organism was not susceptible. MDR phenotypes were defined as nonsusceptibility to $\geq 1$ agent in $\geq 3$ antimicrobial categories, and extensively drug-resistant (XDR) phenotypes were defined as nonsusceptibility to $\geq 1$ agent in all but $\geq 2$ classes.

\section{DNA extraction and whole-genome sequencing}

DNA was extracted from a single colony of each of the 117 A. baumannii isolates using the QIAamp 96 DNA QIAcube HT Kit and the QIAcube HT system (Qiagen; Hilden, Germany). DNA extracts were multiplexed and sequenced on the Illumina HiSeq platform (Illumina; 
Fig. 1. Annual resistance rates of Acinetobacter baumannii to different antibiotics, 2000-2017

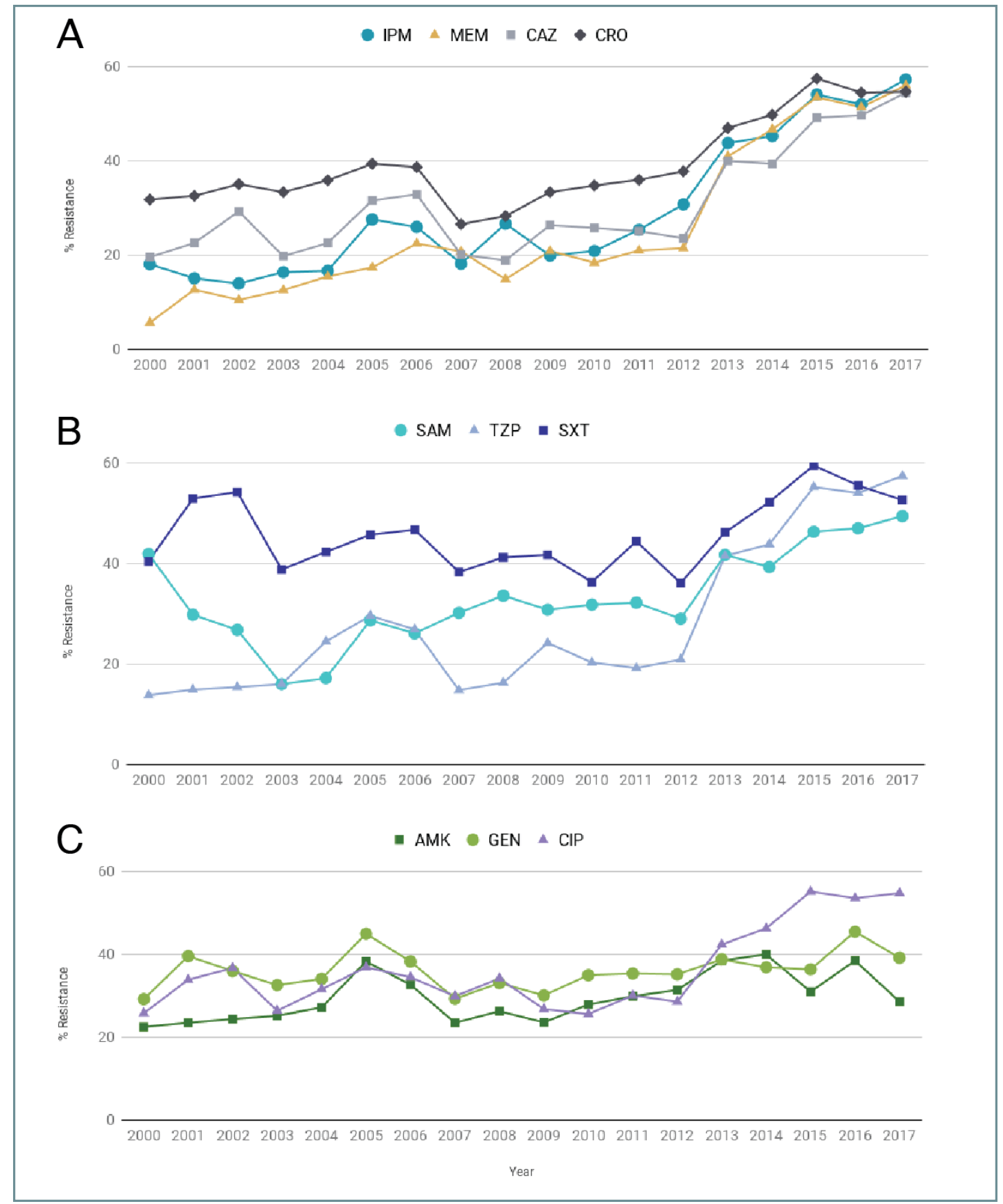

A. IPM: imipenem; MEM: meropenem; CAZ: ceftazidime; CRO: ceftriaxone. B. SAM: ampicillin-sulbactam; TZP: piperacillin-tazobactam; SXT: sulfamethoxazole-trimethoprim. C. AMK: amikacin; GEN: gentamicin; CIP: ciprofloxacin.

San Diego, CA, USA) with 100-base pair paired-end reads. Raw sequence data were deposited in the European Nucleotide Archive under the study accession PRJEB17615. Run accessions are provided through the links to Microreact projects in the figure legends.

\section{Bioinformatics analysis}

Genome quality was assessed based on metrics produced for assemblies, annotation files and the alignment of the reads to the reference genome $A$. baumannii strain ATCC 17978 (GenBank accession CP000521), as previously described. ${ }^{9}$ Annotated assemblies were produced from short-read Illumina data as previously described. ${ }^{11}$

We derived in silico the multilocus sequence type of the isolates from WGS. The sequence types were determined from assemblies using Pathogenwatch (https://pathogen.watch/) or from sequence reads using $\mathrm{ARIBA}^{12}$ and the $A$. baumannii database hosted 
Table 1. Total number of $\boldsymbol{A}$. baumannii isolates analysed by the Antimicrobial Resistance Surveillance Program (ARSP) and referred to the Antimicrobial Resistance Surveillance Reference Laboratory (ARSRL) during 2013 and 2014, isolates submitted for whole-genome sequencing, and high-quality A. baumannii genomes obtained, discriminated by sentinel site and AMR profile.

\begin{tabular}{|c|c|c|c|}
\hline & & ber of is & \\
\hline & 2013 & 2014 & Total \\
\hline A. baumannii total ARSP & 2327 & 2927 & 5254 \\
\hline A. baumannii referred to ARSRL & 155 & 290 & 445 \\
\hline A. baumannii submitted for WGS & 59 & 58 & 117 \\
\hline A. baumannii high-quality genomes & 58 & 50 & 108 \\
\hline By sentinel site ${ }^{a}$ & & & \\
\hline $\mathrm{BGH}$ & 4 & 6 & 10 \\
\hline $\mathrm{CMC}$ & 0 & 1 & 1 \\
\hline CVM & 1 & 0 & 1 \\
\hline DMC & 6 & 2 & 8 \\
\hline FEU & 0 & 1 & 1 \\
\hline GMH & 5 & 1 & 6 \\
\hline JLM & 0 & 2 & 2 \\
\hline MAR & 11 & 3 & 14 \\
\hline $\mathrm{MMH}$ & 2 & 4 & 6 \\
\hline NKI & 1 & 1 & 2 \\
\hline NMC & 1 & 1 & 2 \\
\hline $\mathrm{RMC}$ & 1 & 0 & 1 \\
\hline SLH & 0 & 2 & 2 \\
\hline STU & 3 & 3 & 6 \\
\hline VSM & 13 & 19 & 32 \\
\hline ZMC & 10 & 4 & 14 \\
\hline
\end{tabular}

By AMR profile

\begin{tabular}{lccc} 
CAZ CRO IPM SAM TZP GEN AMK CIP SXT & 48 & 36 & 84 \\
CAZ CRO IPM SAM TZP GEN AMK CIP & 0 & 6 & 6 \\
CRO IPM SAM TZP AMK & 3 & 1 & 4 \\
CAZ CRO IPM SAM TZP GEN CIP & 0 & 3 & 3 \\
SUSceptible & 1 & 1 & 2 \\
CAZ CRO SAM TZP GEN CIP SXT & 1 & 0 & 1 \\
IPM & 0 & 1 & 1 \\
CAZ CRO IPM SAM TZP AMK CIP SXT & 1 & 0 & 1 \\
CRO IPM TZP AMK & 1 & 0 & 1 \\
CAZ CRO SAM TZP GEN AMK & 1 & 0 & 1 \\
IPM TZP & 0 & 1 & 1 \\
CAZ CRO IPM SAM TZP GEN CIP SXT & 1 & 0 & 1 \\
CAZ CRO IPM SAM TZP & 1 & 0 & 1 \\
CAZ CRO IPM TZP & 0 & 1 & 1 \\
\hline
\end{tabular}

a BGH: Baguio General Hospital and Medical Center; CMC: Cotabato Regional Hospital and Medical Center; CVM: Cagayan Valley Medical Center; DMC: Southern Philippines Medical Center; FEU: Far Eastern University Hospital; GMH: Governor Celestino Gallares Memorial Hospital; JLM: Jose B. Lingad Memorial Regional Hospital; MAR: Mariano Marcos Memorial Hospital and Medical Center; MMH: Corazon Locsin Montelibano Memorial Regional Hospital; NKI: National Kidney and Transplant Institute; NMC: Northern Mindanao Medical Center; RMC: Rizal Medical Center; SLH: San Lazaro Hospital; STU: University of Sto. Tomas Hospital; VSM: Vicente Sotto Memorial Medical Center; ZMC: Zamboanga City Medical Center.

${ }^{b}$ AMK: amikacin; CAZ: ceftazidime; CIP: ciprofloxacin; CRO: ceftriaxone; GEN: gentamicin; IPM: imipenem; SAM: ampicillin-sulbactam; SXT: trimethoprim-sulfamethoxazole; TZP: piperacillin-tazobactam. 
at PubMLST.org. ${ }^{13}$ The isolates were assigned to international clones based on their sequence types, as previously described. ${ }^{14-17}$

Evolutionary relationships between isolates were inferred from single-nucleotide polymorphisms (SNPs) by mapping the paired-end reads to the reference genomes of A. baumannii strain A1 (accession CP010781) or AC29 (ST195, CC92, accession CP007535), as described in detail previously. ${ }^{9}$ Mobile genetic elements were masked in the alignment of pseudogenomes with a script available at https://github.com/sanger-pathogens/ remove_blocks_from_aln. Alignments of SNP positions were inferred with SNP-sites v. 2.4.1 (https://github. com/sanger-pathogens/snp-sites). ${ }^{18}$ For the phylogenies of CC92 genomes, recombination regions detected with Gubbins $^{19}$ in the alignment of pseudogenomes were also removed. Maximum likelihood phylogenetic trees were generated with RAxML v. 8.28, ${ }^{20}$ based on the generalised time reversible model with the GAMMA method of correction for among-site rate variation and 100 bootstrap replications. Pairwise SNP differences between primary isolates belonging to the same or different hospitals were calculated from alignments of SNP positions with a script available at https://github. com/simonrharris/pairwise_difference_count.

To contextualize the Philippine genomes, global A. baumannii genomes with geolocation data and an isolation date mainly between 2007 and 2017, for which raw Illumina paired-end sequence data were available at the European Nucleotide Archive, were downloaded, assembled and underwent quality control as described above. Evolutionary relationships between global genomes and those from this study were inferred from an alignment of SNP positions obtained after mapping the reads to the complete genome of strain A1 and masking regions with mobile genetic elements, as described above. The tree of 977 genomes was obtained using an approximately maximum-likelihood phylogenetic method with FastTree. ${ }^{21}$ The tree of 573 global CC92 genomes was inferred with RAxML from an alignment of SNP sites obtained after mapping the genomes to the complete genome of strain AC29 and removing mobile genetic elements and recombination regions, as described above.

Known AMR determinants were identified from raw sequence reads using ARIBA $^{12}$ and two different AMR databases, a curated database of acquired resistance genes $^{22}$ and the Comprehensive Antibiotic Resistance Database (CARD). ${ }^{23}$ Point mutations were identified on gyrase and topoisomerase genes with CARD and ARIBA, and corroborated with a literature search. The presence of the insertion sequences ISAbal (GenBank accession AY758396) and ISAba125 (GenBank accession AY751533) upstream of the ampC gene was examined with ISMapper v. 2.0.1 (24) using the reference genome of $A$. baumannii A1 (GenBank accession CP010781) and default parameters. Genomic predictions of resistance were derived from the presence of known AMR genes and mutations identified in the genome sequences. The genomic predictions of AMR (the test) were compared with the phenotypic results (the reference), and the concordance between the two methods was computed for each of 7 antibiotics (756 total comparisons). For comparison purposes, isolates with either a resistant or an intermediate phenotype were considered nonsusceptible. An isolate with the same outcome for both the test and the reference (i.e. both susceptible or both nonsusceptible) was counted as a concordant isolate. The concordance was the number of concordant isolates over the total number of isolates assessed (expressed as a percentage).

All project data, including inferred phylogenies, AMR predictions and metadata are available through the web application Microreact (http://microreact.org).

\section{RESULTS}

\section{Demographic and clinical characteristics of the isolates}

Out of the 117 A. baumannii genomes sequenced, 7 were excluded based on their quality, and 2 were identified in silico as Acinetobacter pittii (Table 1). The demographic and clinical characteristics of the remaining 108 A. baumannii isolates are summarized in Table 2. The age of the patients ranged from $<1$ year to 92 years old, with $31.48 \%$ of the isolates $(n=34)$ from patients aged $\geq 65$ years. Altogether $62.03 \%$ of the isolates ( $n=67$ ) were from males. The majority of the isolates were from inpatients $(99.07 \% ; n=107)$ and were classified as being from a hospital-acquired infection (76.85\%; $n=83$ ). Respiratory samples (tracheal aspirates and sputum) accounted for $55.56 \%$ of the specimens $(n=60)$. 


\section{Concordance between phenotypic and geno- typic antimicrobial resistance}

The genotypic predictions of AMR were highly concordant with the phenotypic results (overall concordance, $94.97 \%$; Table 3). The concordance for imipenem was $98.15 \%$, and of the 104 resistant isolates, 97 isolates from 14 hospitals (93.26\%) carried the class $D \beta$-lactamase gene bla $a_{0 \times A-23}$ alone or in combination with bla $a_{0 \times A-235}(n=1)$. The remaining isolates carried bla $a_{\mathrm{NDM}-6}(n=3)$, bla NDM-1 $_{1}$ $(n=2)$ or bla oxA-72 $(n=2)$. One isolate had no known acquired carbapenemase. Of the 104 isolates resistant to imipenem, 89 (85.58\%) were classified as XDR and $13(12.50 \%)$ as MDR; also noted were the presence of the armA gene encoding a $16 \mathrm{~S}$ ribosomal RNA methyltransferase, conferring broad-spectrum resistance to aminoglycosides in 54 isolates, and the co-occurrence of mutations in gyrA and parC, conferring resistance to fluoroquinolones in 95 isolates (Table 3). The mobilized colistin resistance gene $(\mathrm{mcr}$ ) was not detected.

The isolates that were nonsusceptible to the third-generation cephalosporins ceftazidime $(n=99)$ or ceftriaxone ( $n=104)$, or both, carried either the insertion sequence ISAbaI upstream of the chromosomal $b / a_{\text {ampc }}$ gene $(n=67)$, two or three copies of the $b / a_{\text {ampc }}$ gene $(n=22)$, the extended-spectrum $\beta$-lactamase genes bla $a_{\text {PER-1 }}(n=4)$ and bla $a_{\text {CTX-M-15 }}(n=1)$ or the carbapenemase gene bla NDM $(n=5)$. Most of the false negative calls for ceftazidime $(n=3)$ and ceftriaxone $(n=8)$ (Table 3$)$, for which no resistance mechanism was detected, coincided with intermediate susceptibility ( $n=2$ and $n=5$, respectively).

\section{Genotypic findings}

In silico genotyping

Multilocus sequence type was predicted in silico from the WGS data of the $108 \mathrm{~A}$. baumannii isolates. A total of 22 different sequence types were identified from this data set as per the Oxford scheme, ${ }^{19} 7$ of which were novel and are now identified as ST2197, 2199, 2220, 2317, 2318, 2319 and 2320. The population was dominated by CC92 $(n=61)$, represented mainly by ST195 ( $n=29$ ) and ST208 $(n=23)$. CC92 was found at 13 of the 16 sentinel sites, with ST195 and ST208 spread geographically across 8 and 7 sentinel sites, respectively. In contrast, ST369 $(n=5)$ was found in only one site.
The armA gene was found only in isolates belonging to CC92 $(n=54)$ and from 11 hospitals. Seven of the eight hospitals represented by six or more sequenced isolates showed clonal diversity, with at least two different circulating sequence types (Table 4), albeit with similar or identical resistance profiles. In contrast, all isolates collected by the Baguio General Hospital and Medical Center (BGH) belonged to sequence type 208 .

Population structure of A. baumannii in the Philippines

The phylogenetic tree of 108 A. baumannii genomes showed that the population was composed of welldefined clades that matched the distribution of the sequence types. The two main clonal groups were IC1 and IC2 (i.e. CC92; Fig. 2a), with a minor representation of IC8 and IC7. Isolates belonging to international clones were mostly XDR and are known to be responsible for disseminating AMR globally. The carbapenemase gene bla ${ }_{0 X A-23}$ was found consistently in IC1 and IC2 genomes, and more sporadically in IC8 and nonclonal genomes. In contrast, the carbapenemase gene b/a $a_{\mathrm{NDM}-6}$ was found exclusively in three IC8 genomes from Corazon Locsin Montelibano Memorial Regional Hospital (MMH), while $b / a_{\mathrm{NDM}-1}$ and $b / a_{0 \times \mathrm{OA}-72}$ were found only sporadically. Notably, isolates carrying ISAbaI inserted in the promoter of bla ampc belonged to ST449 (IC1) or to CC92 (IC2), while isolates carrying two or three copies of the $b / a_{\text {ampc }}$ gene all belonged to a novel sequence type (now ST2199) found in the Vicente Sotto Memorial Medical Center (VSM) in the Visayas region and the Zamboanga City Medical Center in the Mindanao region (Fig. 2a).

The phylogenetic tree of 61 genomes from the prevalent XDR CC92 clone showed that most isolates were grouped into two clades represented by ST208 and single locus variant ST425 (bootstrap support, 96\%) and by ST195 and single locus variant ST369 (bootstrap support, 100\%) (Fig. 2b). Both ST208-ST425 and ST195-ST369 were found in hospitals from all three island groups (Luzon in the north, Visayas in the centre and Mindanao in the south), but their geographical distribution showed little overlap. The phylogeographical signal suggested there were both local outbreaks and interhospital dissemination (Fig. 2b). We investigated this further by counting the number of pairwise, nonrecombinant SNP differences between primary isolates from the same or different hospitals. First, we 
Table 2. Demographic and clinical characteristics of 108 sequenced and confirmed $A$. baumannii isolates collected from 16 ARSP sites

\begin{tabular}{|c|c|}
\hline Characteristic & No. Isolates \\
\hline \multicolumn{2}{|l|}{ Sex } \\
\hline Male & 67 \\
\hline Female & 41 \\
\hline \multicolumn{2}{|l|}{ Age (in years) } \\
\hline$<1$ & 6 \\
\hline $1-4$ & 11 \\
\hline $5-14$ & 3 \\
\hline $15-24$ & 6 \\
\hline $25-34$ & 7 \\
\hline $35-44$ & 9 \\
\hline $45-54$ & 12 \\
\hline $55-64$ & 20 \\
\hline $65-80$ & 26 \\
\hline$\geq 81$ & 8 \\
\hline \multicolumn{2}{|l|}{ Patient Type } \\
\hline In-patient & 107 \\
\hline Out-patient & 1 \\
\hline \multicolumn{2}{|l|}{ Specimen Origin } \\
\hline Community-acquired & 25 \\
\hline Hospital-acquired & 83 \\
\hline \multicolumn{2}{|l|}{ Submitted $\mathrm{As}^{*}$} \\
\hline Carbapenem-resistant & 104 \\
\hline Non carbapenem-resistant & 4 \\
\hline \multicolumn{2}{|l|}{ Specimen Type } \\
\hline Aspirate & 1 \\
\hline Blood** & 21 \\
\hline Bone & 1 \\
\hline Catheter & 1 \\
\hline Catheter, central & 1 \\
\hline Cerebrospinal fluid** & 13 \\
\hline Sputum & 10 \\
\hline Tracheal aspirate & 50 \\
\hline Ulcer & 1 \\
\hline Urine & 4 \\
\hline Wound & 5 \\
\hline
\end{tabular}

* Specimen Origin is computed based on admission date of the patient

** Specimen types considered as Invasive isolates. identified three intrahospital clusters (bootstrap support, $100 \%$ ) of closely related isolates from BGH (ST208, 2-35 pairwise SNPs; $n=9$ ), Southern Philippines Medical Center (DMC, ST208-ST425, 1-6 pairwise SNPs; $n=8$ ) and Mariano Marcos Memorial Hospital and Medical Center (MAR, ST195, 0-3 pairwise SNPs; $n=6)$. The isolates within each of the three clusters carried identical or almost identical repertoires of resistance determinants, further supporting their clonal relationship. The isolation dates spanning more than 12 months suggested that these clonal lineages are possibly endemic to the hospitals, although regular introduction by colonized patients cannot be ruled out.

Next, we identified two clusters of closely related isolates from two or more hospitals. One cluster contained nine ST195 genomes from two hospitals in the Visayas region (MMH and VSM), with a median of only 5 pairwise SNP differences (range, 1-17) between isolates from different hospitals. The second one contained 18 ST195-ST369 genomes from six hospitals across three different regions, with a median of 25 pairwise SNP differences (range, 1-53). The clonal relationship between isolates from different hospitals within these two clusters is also supported by a similar complement of resistance determinants.

\section{A. baumannii from the Philippines in the global context}

To place the retrospective collection of $A$. baumannii isolates from the Philippines in the context of the global population of this pathogen, we compared our genomes to 931 genomes publicly available from sequence data archives that have linked geographical and temporal information. The isolates were collected between 1982 and 2016, with $94.7 \%$ of the isolates collected from 2007 onwards. The public genomes belonged to 16 countries and were assigned to 154 sequence types. The population represented by the global genomes was substantially skewed towards genomes from the United States (40.5\%) and belonging to CC92 (58.6\%). The Philippine genomes were found in multiple branches of the tree, as expected by the diversity of sequence types, but 
Table 3. Comparison between antimicrobial susceptibility testing results and genotypic resistance for 108 A. baumannii isolates.

\begin{tabular}{|c|c|c|c|c|c|c|c|}
\hline Antibiotic class & Antibiotic & $\begin{array}{l}\text { Isolates } \\
\text { tested }\end{array}$ & $\begin{array}{l}\text { Resistant } \\
\text { isolates }\end{array}$ & $\begin{array}{l}\text { False } \\
\text { positive }\end{array}$ & $\begin{array}{c}\text { False } \\
\text { negative }\end{array}$ & $\%$ Concordance & Resistance genes/SNPs \\
\hline $\begin{array}{c}\text { 3rd gen } \\
\text { cephalosporin }\end{array}$ & Ceftazidime & 108 & 99 & 0 & 3 & 97.22 & \multirow{2}{*}{ 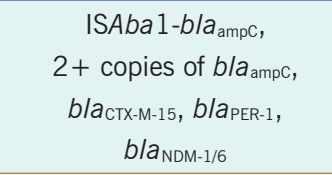 } \\
\hline $\begin{array}{c}\text { 3rd gen } \\
\text { cephalosporin }\end{array}$ & Ceftriaxone & 108 & 104 & 0 & 8 & 92.59 & \\
\hline Carbapenem & Imipenem & 108 & 104 & 1 & 1 & 98.15 & 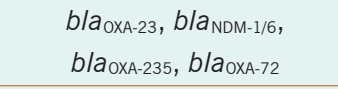 \\
\hline Aminoglycoside & Gentamicin & 108 & 96 & 0 & 10 & 90.74 & $\begin{array}{l}\operatorname{aac}\left(3^{\prime}\right)-l a, \operatorname{aac}\left(3^{\prime}\right)-I /, \\
\operatorname{ant}\left(2^{\prime \prime}\right)-l a, \operatorname{armA}\end{array}$ \\
\hline Aminoglycoside & Amikacin & 108 & 97 & 6 & 0 & 94.44 & $\operatorname{aac}\left(6^{\prime}\right)-I b, a p h(3)-V I$, armA \\
\hline Fluoroquinolone & Ciprofloxacin & 108 & 96 & 0 & 1 & 99.07 & $\begin{array}{c}\text { gyrA_S81L, parC_S84L, } \\
\text { qnrA1 }\end{array}$ \\
\hline $\begin{array}{l}\text { Folate pathway } \\
\text { antagonist }\end{array}$ & $\begin{array}{l}\text { Trimethoprim- } \\
\text { sulfamethoxazole }\end{array}$ & 108 & 87 & 1 & 7 & 92.59 & sul1, sul2, dfrA14, dfrA18 \\
\hline
\end{tabular}

they mostly formed discreet clusters within each branch without genomes from other countries interspersed (Fig. 3a). This suggests that the establishment of each clone in the Philippines is the result of one or only a few founding events.

To investigate in more detail the relationship to global genomes within CC92, a tree of 573 genomes was inferred from the alignment of nonrecombinant SNPs (Fig. 3b). The ST195-ST369 genomes from the Philippines clustered with genomes from China, Malaysia, Singapore, the United States and Viet Nam, while the ST208-ST425 genomes were related to genomes from China, Puerto Rico and the United States. However, the strong phylogeographical signal displayed by both the ST195-ST369 and the ST208-ST425 subtrees suggested a single founder event in the Philippines for each clone, followed by their expansion.

\section{DISCUSSION}

This study reports on the combined genomic and laboratory-based surveillance of $A$. baumannii in the Philippines during 2013-2014. The prevalence of carbapenem-resistant $A$. baumannii during this period was above $40 \%$, and we therefore focused on characterizing these organisms. In A. baumannii, only low-level carbapenem resistance is mediated by the chromosomal OXA-51-like carbapenemase. The class D OXA-23 carbapenemase was the most prevalent acquired carbapenem resistance mechanism identified in this study, in line with global trends. ${ }^{25}$ We also detected representatives from the OXA-235-like ( $\left(b / a_{0 \times A-235}\right)$ and the OXA-40-like (bla $\left.a_{0 \times A-72}\right)$ groups, albeit in low frequency. No OXA-58-like carbapenemases were detected, as previously reported from other Asia-Pacific nations. ${ }^{26}$ Importantly, we also detected the presence of the class B metallo- $\beta$-lactamases NDM- 1 and NDM- 6 , which, unlike OXA-23, confer resistance to extended-spectrum cephalosporins as well as carbapenems. A. baumannii harbouring NDM-1 has been sporadically reported previously from other countries, ${ }^{27-29}$ but NDM-6-carrying A. baumannii has only recently been reported from Spain. ${ }^{30}$ Resistance to extended-spectrum cephalosporins was mainly explained by the insertion of ISAbal in the promoter of the intrinsic gene $b / a_{\text {ampc }}$, which has been shown to lead to increased expression of the encoded cephalosporinase. $^{31}$ Identification of this mechanism represents an additional in silico query of the genomes, which is burdensome in the context of a public health reference laboratory, but omitting it would lead to high major error rates for genomic predictions of resistance to extended-spectrum cephalosporins.

Both IC1 and IC2, which are responsible for the spread of MDR and XDR phenotypes worldwide, ${ }^{25,32}$ were found in the Philippines. However, IC2 was the predominant clonal type of $A$. baumannii in our study population, with ST195 and ST208 and their respective single locus variants found throughout the country. The global phylogenetic tree showed that these two lineages diverged before their establishment in the Philippines. The genetic relatedness of isolates from different hospitals and their similar complements of resistance determinants 
Table 4. The summary of distribution, sequence types (ST), resistance profiles and antimicrobial resistance genes and mutations of the 108 isolates collected from 16 Antimicrobial Resistance Surveillance Program sentinel sites.

\begin{tabular}{|c|c|c|c|c|c|}
\hline Site ${ }^{a}$ & $\begin{array}{l}\text { No. of } \\
\text { isolates }\end{array}$ & $\begin{array}{l}\text { No. of } \\
\text { STs }\end{array}$ & ST $(n)$ & $\begin{array}{l}\text { Resistance profiles } \\
\text { ( } n)\end{array}$ & $\begin{array}{l}\text { Acquired resistance mechanisms } \\
\qquad(n)\end{array}$ \\
\hline \multirow[t]{4}{*}{ BGH } & 10 & 1 & $208(10)$ & $\begin{array}{l}\text { CAZ CRO IPM SAM TZP } \\
\text { GEN AMK CIP SXT (9) }\end{array}$ & $\begin{array}{l}\text { ISAba1-blaampc, blaoxA-23, aac(6')-Ib, aph(3')-VI, } \\
\text { armA, gyrA_S81L, parC_S84L, sul1, sul2 (6) }\end{array}$ \\
\hline & & & & & $\begin{array}{l}\text { ISAba1-blaampc, blaoxA-23, aac(6')-Ib, aph(3')-VI, } \\
\text { armA, gyrA_S81L, parC_S84L, sul1 (2) }\end{array}$ \\
\hline & & & & & $\begin{array}{l}\text { ISAba1-bla ampc, bla axA-23, aac(6')-Ib, armA, gyrA } \\
\text { S81L, parC_S84L, sul1, sul2 (1) }\end{array}$ \\
\hline & & & & $\begin{array}{l}\text { CAZ CRO IPM SAM TZP } \\
\text { AMK CIP SXT (1) }\end{array}$ & $\begin{array}{l}\text { ISAba1-bla ampc, blaoxA-23, aph(3')-VI, gyrA_S81L, } \\
\text { parC_S84L, sul2 (1) }\end{array}$ \\
\hline $\mathrm{CMC}$ & 1 & 1 & $2319(1)$ & CAZ CRO IPM TZP (1) & blaoxA-72 (1) \\
\hline CVM & 1 & 1 & $957(1)$ & $\begin{array}{l}\text { CAZ CRO SAM TZP GEN } \\
\text { AMK (1) }\end{array}$ & bla $a_{\text {PER-1 }}, \operatorname{aac}(3)-I I, \operatorname{aph}\left(3^{\prime}\right)-V I, \operatorname{sul} 1$ (1) \\
\hline \multirow[t]{2}{*}{ DMC } & 8 & 2 & $208(7)$ & $\begin{array}{l}\text { CAZ CRO IPM SAM TZP } \\
\text { GEN AMK CIP SXT ( } 7 \text { ) }\end{array}$ & $\begin{array}{l}\text { ISAba1-blaampc, blaoxA-23, aac(6')-Ib, armA, gyrA } \\
\text { S81L, parC_S84L, sul1 (7) }\end{array}$ \\
\hline & & & $425(1)$ & $\begin{array}{l}\text { CAZ CRO IPM SAM TZP } \\
\text { GEN AMK CIP SXT (1) }\end{array}$ & $\begin{array}{l}\text { ISAba1-blaampc, blaoxA-23, aac(6')-Ib, armA, gyrA_ } \\
\text { S81L, parC_S84L, sul1 (1) }\end{array}$ \\
\hline FEU & 1 & 1 & 208 & $\begin{array}{l}\text { CAZ CRO IPM SAM TZP } \\
\text { GEN CIP (1) }\end{array}$ & $\begin{array}{l}\text { ISAba1-bla ampc, bla oxA-23, gyrA_S81L, parC_S84L } \\
\text { (1) }\end{array}$ \\
\hline \multirow[t]{6}{*}{ GMH } & 6 & 6 & $2174(1)$ & CRO IPM SAM TZP AMK (1) & $b / a_{0 \times A-23}, a p h\left(3^{\prime}\right)-V I(1)$ \\
\hline & & & $2197(1)$ & CRO IPM SAM TZP AMK & bla ${ }_{0 \times A-23}, a p h\left(3^{\prime}\right)-V I(1)$ \\
\hline & & & $2318(1)$ & CRO IPM SAM TZP AMK & bla ${ }_{0 \times A-23}, a p h\left(3^{\prime}\right)-V I(1)$ \\
\hline & & & $2320(1)$ & CRO IPM SAM TZP AMK & blaoxA-23, aph(3')-VI (1) \\
\hline & & & $2317(1)$ & CRO IPM TZP AMK & bla oxA-23, aph(3')-VI (1) \\
\hline & & & ND (1) & CAZ CRO IPM SAM TZP & bla NDM-1, $\operatorname{aph}\left(3^{\prime}\right)-V I(1)$ \\
\hline \multirow[t]{2}{*}{ JLM } & 2 & 2 & $195(1)$ & $\begin{array}{l}\text { CAZ CRO IPM SAM TZP } \\
\text { GEN AMK CIP (1) }\end{array}$ & $\begin{array}{l}\text { ISAba 1-bla ampc, blaoxA-23, armA, gyrA_S81L, } \\
\text { parC_S84L (1) }\end{array}$ \\
\hline & & & $208(1)$ & $\begin{array}{l}\text { CAZ CRO IPM SAM TZP } \\
\text { GEN AMK CIP SXT (1) }\end{array}$ & $\begin{array}{l}\text { ISAba1-blaampc, blaoxA-23, aac(6')-Ib, armA, gyrA_ } \\
\text { S81L, parC_S84L, sul1 (1) }\end{array}$ \\
\hline \multirow[t]{6}{*}{ MAR } & 14 & 5 & $195(6)$ & $\begin{array}{l}\text { CAZ CRO IPM SAM TZP } \\
\text { GEN AMK CIP SXT (6) }\end{array}$ & $\begin{array}{l}\text { ISAba1-bla ampc, blaoxA-23, armA, gyrA_S81L, } \\
\text { parC_S84L, sul2 (5) }\end{array}$ \\
\hline & & & & & $\begin{array}{l}\text { ISAba 1-bla } a_{\text {ampc }}, b / a_{0 \times A-23}, a r m A, g y r A \_S 81 \mathrm{~L}, \\
\text { parC_S84L (1) }\end{array}$ \\
\hline & & & $449(5)$ & $\begin{array}{l}\text { CAZ CRO IPM SAM TZP } \\
\text { GEN AMK CIP SXT (5) }\end{array}$ & $\begin{array}{l}\text { ISAba 1-blaampc, blaoxA-23, ant(2")-la, aph(3')-VI, } \\
\text { gyrA_S81L, sul1 (5) }\end{array}$ \\
\hline & & & $447(1)$ & $\begin{array}{l}\text { CAZ CRO IPM SAM TZP } \\
\text { GEN AMK CIP SXT (1) }\end{array}$ & $\begin{array}{l}\text { blandM-1, aph(3')-VI, gyrA_S81L, parC_S84L, } \\
\text { sul2 (1) }\end{array}$ \\
\hline & & & $391 *(1)$ & $\begin{array}{l}\text { CAZ CRO IPM SAM TZP } \\
\text { GEN AMK CIP SXT (1) }\end{array}$ & $\begin{array}{l}\text { blactX-M-15, bla per-1, blaoxA-23, aac(3)-II, aac(6')-Ib, } \\
\text { aph(3')-VI, gyrA_S81L, parC_S84L, gnrA1, sul1, } \\
\text { sul2, dfrA14 (1) }\end{array}$ \\
\hline & & & $2197(1)$ & Susceptible & blaoxA-23, aph(3')-VI (1) \\
\hline \multirow[t]{3}{*}{$\mathrm{MMH}$} & 6 & 2 & $195(3)$ & $\begin{array}{l}\text { CAZ CRO IPM SAM TZP } \\
\text { GEN AMK CIP SXT (3) }\end{array}$ & $\begin{array}{l}\text { ISAba1-bla ampc, bla } a_{0 \times A-23}, a r m A, g y r A \_S 81 \mathrm{~L}, \\
\text { parC_S84L (3) }\end{array}$ \\
\hline & & & $642(3)$ & $\begin{array}{l}\text { CAZ CRO IPM SAM TZP } \\
\text { GEN AMK CIP (2) }\end{array}$ & bla $a_{\mathrm{NDM}-6}$, aph(3')-VI, gyrA_S81L, parC_S84L (2) \\
\hline & & & & $\begin{array}{l}\text { CAZ CRO IPM SAM TZP } \\
\text { GEN CIP }\end{array}$ & bla \\
\hline \multirow[t]{2}{*}{ NKI } & 2 & 2 & $195(1)$ & $\begin{array}{l}\text { CAZ CRO IPM SAM TZP } \\
\text { GEN AMK CIP SXT (1) }\end{array}$ & $\begin{array}{l}\text { ISAba1-bla ampc, bla oxA-23, armA, gyrA_S81L, } \\
\text { parC_S84L, sul2 (1) }\end{array}$ \\
\hline & & & $208(1)$ & $\begin{array}{l}\text { CAZ CRO IPM SAM TZP } \\
\text { GEN AMK CIP SXT (1) }\end{array}$ & $\begin{array}{l}\text { ISAba1-bla ampc, bla } a_{0 X A-23} \text {, aph(3')-VI, armA, gyrA } \\
\text { S81L, parC_S84L, sul2 (1) }\end{array}$ \\
\hline
\end{tabular}




\begin{tabular}{|c|c|c|c|c|c|}
\hline Site $^{\mathrm{a}}$ & $\begin{array}{l}\text { No. of } \\
\text { isolates }\end{array}$ & $\begin{array}{l}\text { No. of } \\
\text { STs }\end{array}$ & ST $(n)$ & $\begin{array}{l}\text { Resistance profiles }^{b} \\
(n)\end{array}$ & $\begin{array}{l}\text { Acquired resistance mechanisms } \\
(n)\end{array}$ \\
\hline \multirow[t]{2}{*}{ NMC } & 2 & 1 & 208 & $\begin{array}{l}\text { CAZ CRO IPM SAM TZP } \\
\text { GEN AMK CIP SXT (1) }\end{array}$ & $\begin{array}{l}\text { ISAba1-bla ampc, blaoxA-23, aph(3')-VI, gyrA_S81L, } \\
\text { parC_S84L, sul2 (1) }\end{array}$ \\
\hline & & & & $\begin{array}{l}\text { CAZ CRO SAM TZP GEN CIP } \\
\text { SXT ( } 1 \text { ) }\end{array}$ & $\begin{array}{l}\text { ISAba1-bla ampc, aac(3)-la, gyrA_S81L, parC_ } \\
\text { S84L, sul1, sul2 (1) }\end{array}$ \\
\hline RMC & 1 & 1 & 1128 & $\begin{array}{l}\text { CAZ CRO IPM SAM TZP } \\
\text { GEN AMK CIP SXT (1) }\end{array}$ & $\begin{array}{l}\text { ISAba1-bla ampc, bla oxA-23, aph(3')-VI, armA, gyrA } \\
\text { S81L, parC_S84L, sul1, sul2 (1) }\end{array}$ \\
\hline \multirow[t]{2}{*}{ SLH } & 2 & 2 & $195(1)$ & $\begin{array}{l}\text { CAZ CRO IPM SAM TZP } \\
\text { GEN AMK CIP SXT (1) }\end{array}$ & $\begin{array}{l}\text { ISAba1-blaampc, blaoxA-23, armA, gyrA_S81L, } \\
\text { parC_S84L, sul2 (1) }\end{array}$ \\
\hline & & & $642(1)$ & $\begin{array}{l}\text { CAZ CRO IPM SAM TZP } \\
\text { GEN AMK CIP SXT (1) }\end{array}$ & $\begin{array}{l}\text { blaoxA-23, blaoxA-235, aac(6')-Ib, aph(3')-VI, gyrA } \\
\text { S81L, parC_S84L, sul1, sul2, dfrA18 (1) }\end{array}$ \\
\hline \multirow[t]{5}{*}{ STU } & 6 & 3 & $195(3)$ & $\begin{array}{l}\text { CAZ CRO IPM SAM TZP } \\
\text { GEN AMK CIP SXT (3) }\end{array}$ & $\begin{array}{l}\text { ISAba1-bla ampc, blaoxA-23, armA, gyrA_S81L, } \\
\text { parC_S84L, sul2 (2) }\end{array}$ \\
\hline & & & & & $\begin{array}{l}\text { ISAba1-bla }{ }_{\text {ampc }}, \text { bla } \text { oxA-23, } \text { armA, gyrA_S81L, } \\
\text { parC_S84L, sul1, sul2 (1) }\end{array}$ \\
\hline & & & $1289(2)$ & $\begin{array}{l}\text { CAZ CRO IPM SAM TZP } \\
\text { GEN AMK CIP SXT (2) }\end{array}$ & $\begin{array}{l}\text { ISAba1-bla ampc, blapeR-1, blaoxA-23, aac(3)-Ia, } \\
\text { aac(6')-Ib, aph(3')-VI, gyrA_S81L, parC_S84L, } \\
\text { sul1, sul2, dfrA18 (1) }\end{array}$ \\
\hline & & & & & $\begin{array}{l}\text { ISAba1-bla ampc, blapeR-1, blaoxA-23, aac(3)-la, } \\
\text { aac(6')-Ib, gyrA_S81L, parC_S84L, sul1, sul2, } \\
\text { dfrA18 (1) }\end{array}$ \\
\hline & & & $449(1)$ & $\begin{array}{l}\text { CAZ CRO IPM SAM TZP } \\
\text { GEN AMK CIP SXT (1) }\end{array}$ & $\begin{array}{l}\text { ISAba1-bla ampc, blaoxA-23, ant(2")-la, aph(3')-VI, } \\
\text { gyrA_S81L, sul1 (1) }\end{array}$ \\
\hline \multirow[t]{15}{*}{ VSM } & 32 & 6 & $\begin{array}{c}2199 \\
(20)\end{array}$ & $\begin{array}{l}\text { CAZ CRO IPM SAM TZP } \\
\text { GEN AMK CIP SXT (19) }\end{array}$ & $\begin{array}{l}2 \text { copies of bla ampc, blaoxa-23, aac(3)-la, aph(3')- } \\
\text { VI, gyrA_S81L, parC_S84L, sul1 (15) }\end{array}$ \\
\hline & & & & & $\begin{array}{l}2 \text { copies of bla ampc, blaoxa-23, aac(3)-la, aph(3')- } \\
\text { VI, gyrA_S81L, parC_S84L, sul1 (2) }\end{array}$ \\
\hline & & & & & $\begin{array}{l}2 \text { copies of bla ampc, aac(3)-la, aph(3')-VI, gyrA } \\
\text { S81L, parC_S84L, sul1 (1) }\end{array}$ \\
\hline & & & & & $\begin{array}{l}2 \text { copies of bla ampc, bla oxa-23, aph(3')-VI, gyrA } \\
\text { S81L, parC_S84L, sul1 (1) }\end{array}$ \\
\hline & & & & $\begin{array}{l}\text { CAZ CRO IPM SAM TZP } \\
\text { GEN CIP SXT ( } 1 \text { ) }\end{array}$ & $\begin{array}{l}2 \text { copies of bla ampc, blaoxa-23, aac(3)-la, aph(3')- } \\
\text { VI, gyrA_S81L, parC_S84L, sul1 (1) }\end{array}$ \\
\hline & & & $195(7)$ & $\begin{array}{l}\text { CAZ CRO IPM SAM TZP } \\
\text { GEN AMK CIP SXT ( } 4 \text { ) }\end{array}$ & $\begin{array}{l}\text { ISAba1-bla ampc, blaoxA-23, armA, gyrA_S81L, } \\
\text { parC_S84L (2) }\end{array}$ \\
\hline & & & & & $\begin{array}{l}\text { ISAba1-bla ampc, blaoxA-23, aac(3)-la, armA, gyrA } \\
\text { S81L, parC_S84L, sul1 (1) }\end{array}$ \\
\hline & & & & & $\begin{array}{l}\text { ISAba 1-bla ampc, blaoxA-23, armA, gyrA_S81L, } \\
\text { parC_S84L, sul2 (1) }\end{array}$ \\
\hline & & & & $\begin{array}{l}\text { CAZ CRO IPM SAM TZP } \\
\text { GEN AMK CIP (2) }\end{array}$ & $\begin{array}{l}\text { ISAba 1-b/a ampc, blaoxA-23, armA, gyrA_S81L, } \\
\text { parC_S84L (2) }\end{array}$ \\
\hline & & & & $\begin{array}{l}\text { CAZ CRO IPM SAM TZP } \\
\text { GEN CIP (1) }\end{array}$ & $\begin{array}{l}\text { ISAba1-bla ampc, blaoxA-23, armA, gyrA_S81L, } \\
\text { parC_S84L (1) }\end{array}$ \\
\hline & & & $310(2)$ & $\begin{array}{l}\text { CAZ CRO IPM SAM TZP } \\
\text { GEN AMK CIP SXT (1) }\end{array}$ & bla ${ }_{0 \times A-23}, a p h\left(3^{\prime}\right)-V I(1)$ \\
\hline & & & & IPM TZP (1) & bla oхA-23, aph(3')-VI (1) \\
\hline & & & $208(1)$ & $\begin{array}{l}\text { CAZ CRO IPM SAM TZP } \\
\text { GEN AMK CIP SXT (1) }\end{array}$ & $\begin{array}{l}\text { ISAba1-bla ampc, blaoxA-23, aph(3')-VI, gyrA_S81L, } \\
\text { parC_S84L, sul2 (1) }\end{array}$ \\
\hline & & & $229(1)$ & IPM (1) & $b / a_{0 \times A-72}(1)$ \\
\hline & & & $1418(1)$ & $\begin{array}{l}\text { CAZ CRO IPM SAM TZP } \\
\text { GEN AMK CIP (1) }\end{array}$ & $\begin{array}{l}2 \text { copies of bla ampc, blaoxA-23, ant(2")-la, aph(3')- } \\
\text { VI, gyrA_S81L, parC_S84L (1) }\end{array}$ \\
\hline
\end{tabular}




\begin{tabular}{|c|c|c|c|c|c|}
\hline Site $^{a}$ & $\begin{array}{c}\text { No. of } \\
\text { isolates }\end{array}$ & $\begin{array}{l}\text { No. of } \\
\text { STs }\end{array}$ & $\mathrm{ST}(n)$ & $\begin{array}{l}\text { Resistance profiles } \\
(n)\end{array}$ & $\begin{array}{l}\text { Acquired resistance mechanisms } \\
(n)\end{array}$ \\
\hline \multirow[t]{4}{*}{ ZMC } & 14 & 3 & $195(7)$ & $\begin{array}{l}\text { CAZ CRO IPM SAM TZP } \\
\text { GEN AMK CIP SXT ( } 7 \text { ) }\end{array}$ & $\begin{array}{l}\text { ISAba1-bla ampc, blaoxA-23, armA, gyrA_S81L, } \\
\text { parC_S84L, sul2 (7) }\end{array}$ \\
\hline & & & $369(5)$ & $\begin{array}{l}\text { CAZ CRO IPM SAM TZP } \\
\text { GEN AMK CIP SXT (5) }\end{array}$ & $\begin{array}{l}\text { ISAba1-bla ampc, bla oxA-23, armA, gyrA_S81L, } \\
\text { parC_S84L, sul2 (5) }\end{array}$ \\
\hline & & & $2199(1)$ & $\begin{array}{l}\text { CAZ CRO IPM SAM TZP } \\
\text { GEN AMK CIP SXT }\end{array}$ & $\begin{array}{l}2 \text { copies of bla ampc, bla oxA-23, aac(3)-la, aph(3')- } \\
\text { VI, gyrA_S81L, parC_S84L, sul1 }\end{array}$ \\
\hline & & & $2220(1)$ & Susceptible & None detected \\
\hline
\end{tabular}

a BGH: Baguio General Hospital and Medical Center; CMC: Cotabato Regional Hospital and Medical Center; CVM: Cagayan Valley Medical Center; DMC: Southern Philippines Medical Center; FEU: Far Eastern University Hospital; GMH: Governor Celestino Gallares Memorial Hospital; JLM: Jose B. Lingad Memorial Regional Hospital; MAR: Mariano Marcos Memorial Hospital and Medical Center; MMH: Corazon Locsin Montelibano Memorial Regional Hospital; NKI: National Kidney and Transplant Institute; NMC: Northern Mindanao Medical Center; RMC: Rizal Medical Center; SLH: San Lazaro Hospital; STU: University of Sto. Tomas Hospital; VSM: Vicente Sotto Memorial Medical Center; ZMC: Zamboanga City Medical Center.

${ }^{b}$ AMK: amikacin; CAZ: ceftazidime; CIP: ciprofloxacin; CRO: ceftriaxone; GEN: gentamicin; IPM: imipenem; SAM: ampicillin-sulbactam; SXT: trimethoprim-sulfamethoxazole; TZP: piperacillin-tazobactam.

support the notion that their subsequent success was the result of clonal expansion and in-country geographical dissemination, rather than multiple introductions. This highlights the need for concerted infection prevention and control measures to contain the spread of high-risk clones. However, the limited number and disparate sampling of genomes from other countries in the region and the selective referral of carbapenem-resistant isolates to the reference laboratory by the sentinel sites limited our ability to capture the dynamics of these clones.

We also identified three ST195 and ST208 intrahospital clusters spanning more than 12 months each. Resistance to antimicrobial drugs and to desiccation contribute to the survival of $A$. baumannii in the hospital environment, ${ }^{1}$ and cross-contamination of hospital surfaces with MDR strains has been documented, particularly in the areas surrounding colonized or infected patients. ${ }^{33,34}$ The ARSP does not currently include environmental samples, and thus it was not possible to connect the persistence of the intrahospital clusters to environmental contamination, which is a limitation of our

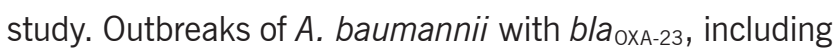
of ST195 and ST208, have been reported from several countries, ${ }^{35-37}$ and our study identified potential hospital outbreaks retrospectively. The resolution afforded by WGS was in stark contrast to the uniform resistance profiles of the isolates in our study, thus making cluster detection based on WGS rather than resistance profiles, of particular utility for carbapenem-resistant A. baumannii.

The assignment of isolates to an outbreak based on their genetic distance is key for effective patient containment and infection control during an ongoing investigation. Out of the three intrahospital IC2 clusters detected, the ST208 cluster from BGH displayed more genetic diversity than the other two, based on the number of pairwise SNP differences, opening the possibility that more than one closely related strain was circulating in the hospital. However, the absence of data on patient movement precluded the epidemiological investigation that would have aided in delineating the outbreaks, another limitation of our study. In addition, while the pairwise SNP differences are similar to those reported in other studies, ${ }^{36,38-40}$ SNP thresholds are difficult to assess by comparison due to methodological differences, such as the use of core- versus whole-genome SNPs, the choice of reference genome for reference-based mapping of short reads, and the inclusion or exclusion of SNPs associated with recombination regions.

In conclusion, our retrospective genomic epidemiology study of carbapenem-resistant $A$. baumannii in the Philippines revealed that IC2 with OXA-23 is the main source of the increasing carbapenem resistance in the Philippines and that breaches in infection control and prevention likely contributed to its dissemination. WGS proved a useful tool for improving surveillance of A. baumannii.

\section{Funding}

This work was supported by a Newton Fund award from the Medical Research Council (UK) MR/N019296/1 and the Philippine Council for Health Research and Development. This work was also partially supported by research grant U01CA207167 from the U.S. National Institutes of Health. The contents are solely the responsibility of the authors and do not necessarily represent the official views of the funders. The funders had no role in study design, data collection and analysis, or decision to pub- 
Fig. 2. Genomic surveillance of $A$. baumannii from the Philippines, 2013-2014

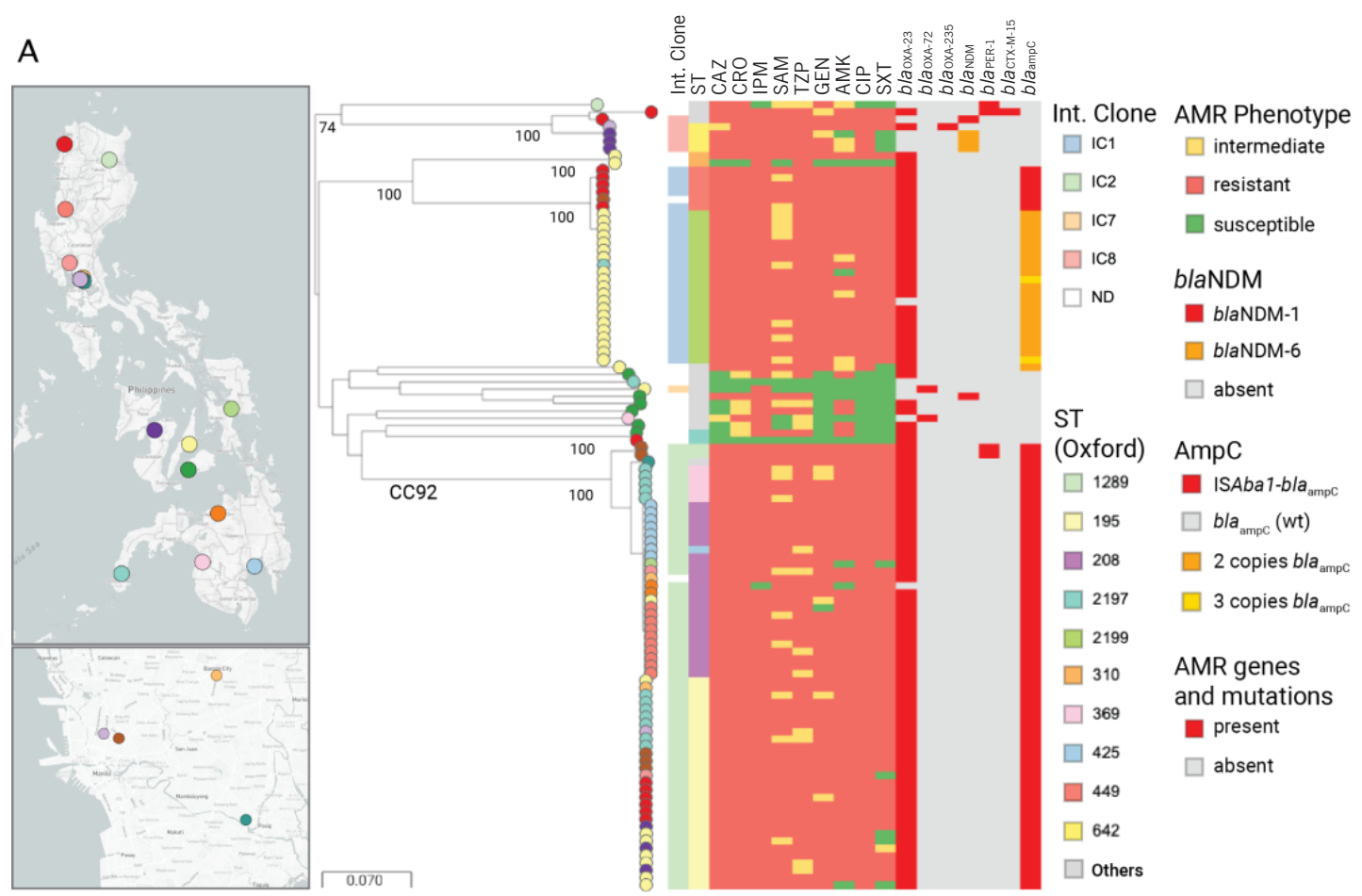

B

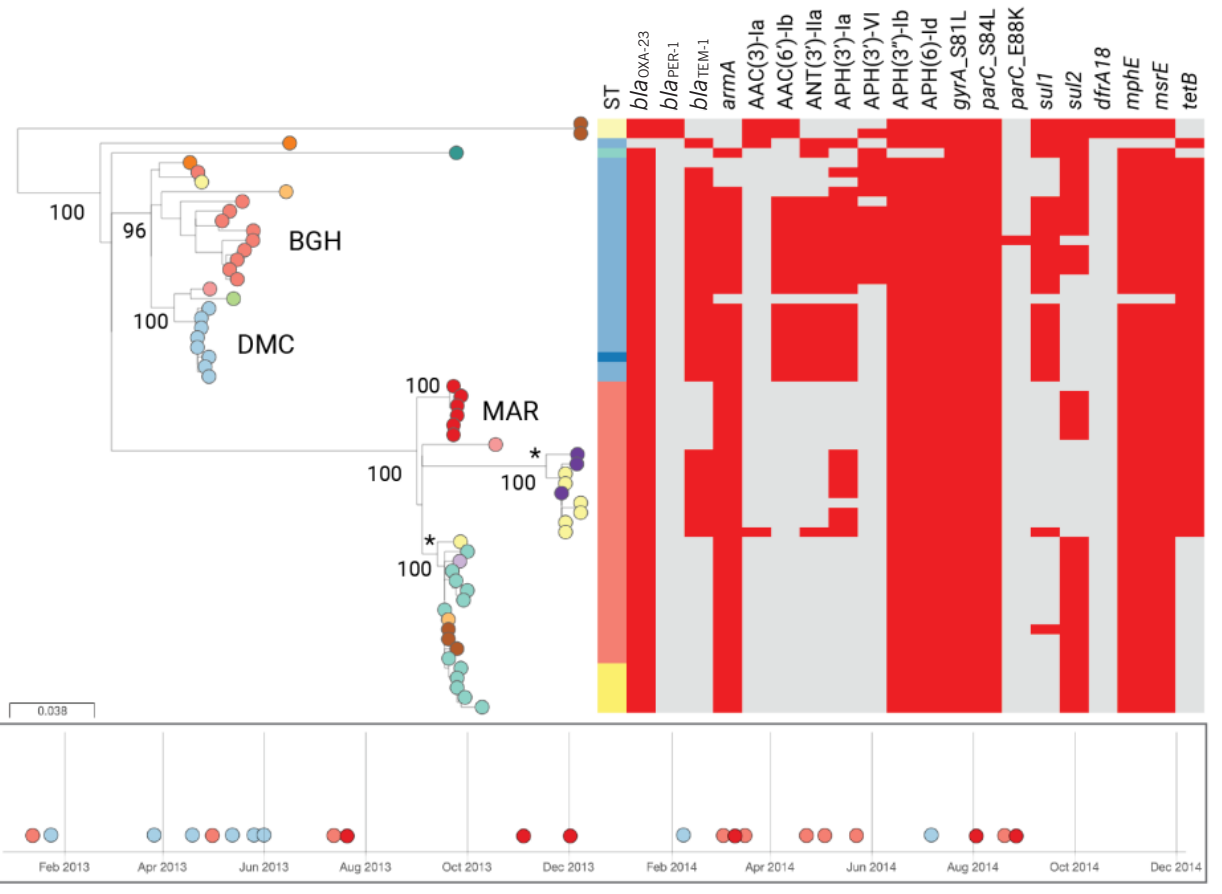

A) Phylogenetic tree of 108 isolates inferred from an alignment of 168916 single nucleotide polymorphism (SNP) sites obtained after mapping the genomes to the complete genome of strain A1 and masking mobile genetic elements from the alignment. The tree leaves are coloured by sentinel site and indicated on the map (top: Philippines; bottom: detail of the National Capital Region). The tree is annotated with the isolates assigned to international clones and sequence types, the results of susceptibility testing and the presence of acquired carbapenemase genes. AMK: amikacin; AMR: antimicrobial resistance; CAZ: ceftazidime; CIP: ciprofloxacin; CRO: ceftriaxone; GEN: gentamicin; IC: international clone; IPM: imipenem; SAM: ampicillin-sulbactam; ST: sequence type; SXT: sulfamethoxazole-trimethoprim; TZP: piperacillin-tazobactam. The full data are available at https://microreact.org/project/ARSP ABA 2013-2014.

B) Phylogenetic tree of 61 clonal complex 92 (CC92) genomes, inferred from an alignment of 618 SNP sites after mapping the genomes to reference AC29 and removing mobile genetic elements and recombination regions. The tree leaves are coloured by sentinel site, as indicated on the map in panel (a). The tree blocks represent the distribution of STs and of acquired resistance genes and mutations. Three hospital clusters are annotated on the tree with the hospital code (BGH: Baguio General Hospital and Medical Center; DMC: Southern Philippines Medical Center; MAR: Mariano Marcos Memorial Hospital and Medical Center), and their isolation dates are indicated on the timeline. Two multihospital clusters are annotated with an asterisk. The full data are available at https://microreact.org/project/ARSP_ABA_CC92_2013-2014. The scale bars represent the number of SNPs per variable site. 


\section{Fig. 3. A. baumannii from the Philippines in global context}

A

\section{Country \\ $\square$ Australia \\ $\square$ China}

$\square$ Czech Republic

$\square$ Germany

$\square$ Greece

$\square$ Japan

$\square$ Malaysia

$\square$ Nepal

$\square$ Netherlands

- Philippines

$\square$ Puerto Rico

Singapore

$\square$ USA

$\square$ United Arab Emirates

United Kingdom

$\square$ Viet Nam

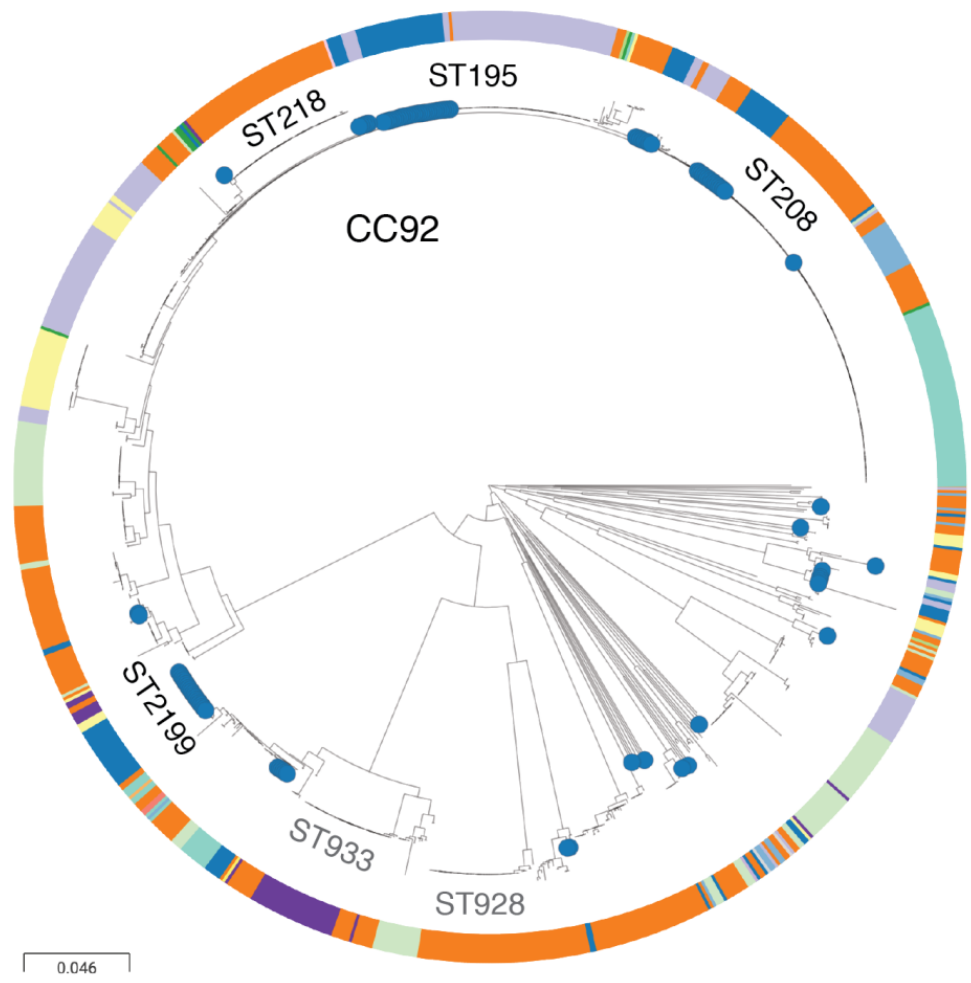

B

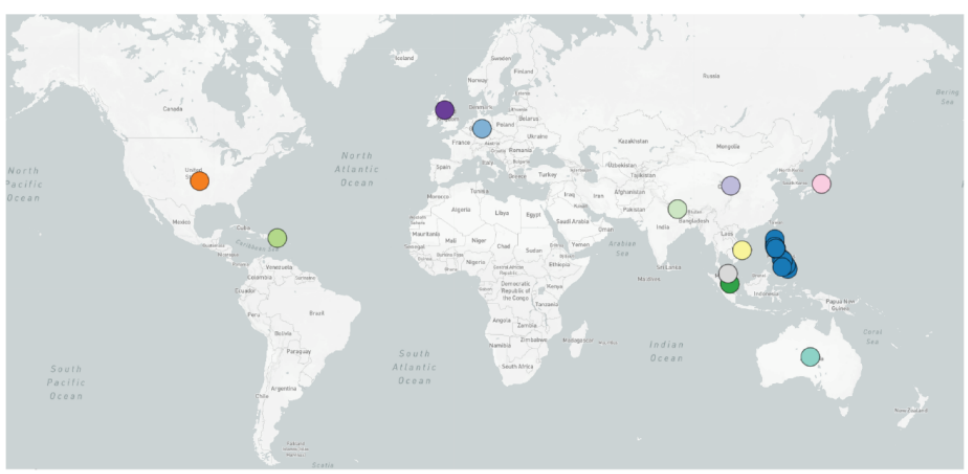

ST (Oxford) bla OXA-23, bla OXA-72,

$\square 191$

$\square 195$

bla $\mathrm{NDM}-1, b / a_{\mathrm{KPC}-2}$

$\square 208$

present

$\square 218$

$\square$ absent

$\square 281$

$\square 350$

$\square 369$

$\square 425$

493

$\square 784$

$\square 848$

$\square$ Others
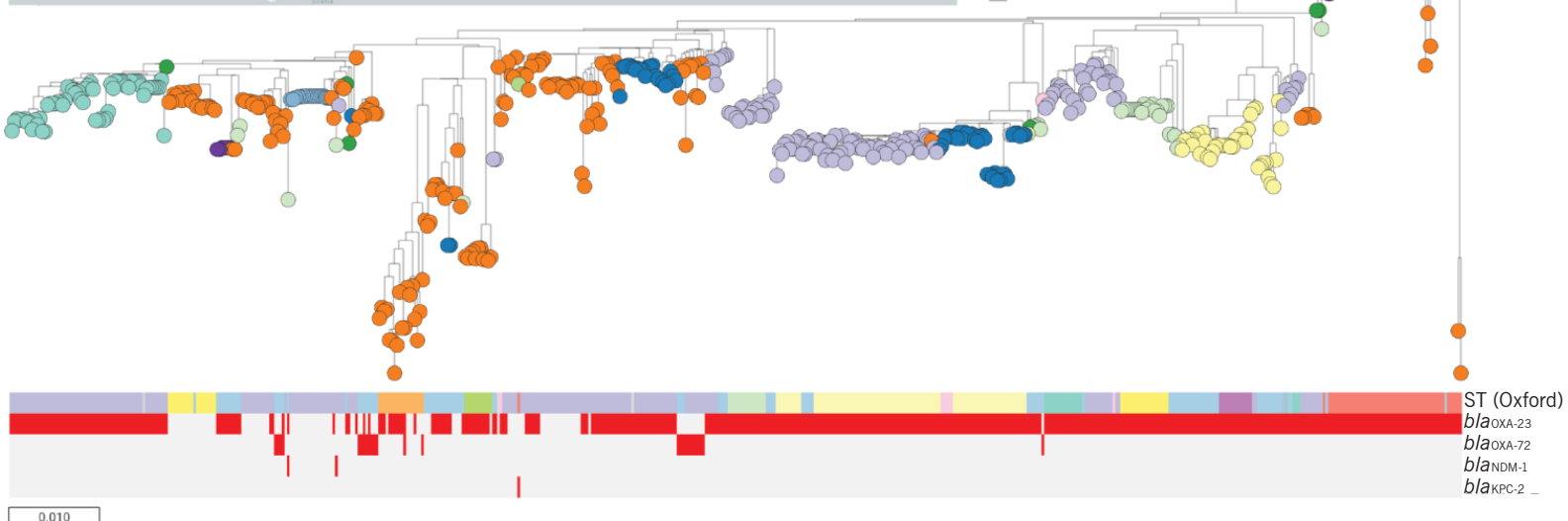

A) Phylogenetic tree of 977 isolates from the Philippines (blue nodes) and from 15 other countries inferred from 305031 SNP positions. The major STs and CCs are labelled in black if represented by genomes of this study, or in grey if they are not. The data are available at https://microreact.org/project/ARSP_ABA_Global.

B) Phylogenetic tree of 573 CC92 isolates inferred from an alignment of 5890 SNP positions. The tree leaves are coloured by country as indicated on the map. The tree is annotated with the distribution of acquired carbapenemase genes (red: present, grey: absent). The data are available at https://microreact.org/project/ARSP_CC92_ Global. The scale bars represent the number of SNPs per variable site. 
lish, or preparation of the manuscript. S.A. and D.M.A. were additionally supported by the National Institute for Health Research (UK) Global Health Research Unit on genomic Surveillance of AMR (16_136_111) and by the Centre for Genomic Pathogen Surveillance.

\section{Conflicts of Interest}

The authors have no conflicting affiliations or financial or non-financial interests in the subject matter discussed in this manuscript.

\section{Ethics Statement}

Ethical approval is not applicable. This study uses archived bacterial samples processed by ARSP. No identifiable data were used in this study.

\section{References}

1. Peleg AY, Seifert H, Paterson DL. Acinetobacter baumannii: emergence of a successful pathogen. Clin Microbiol Rev. 2008;21(3):538-82. doi:10.1128/CMR.00058-07

2. Chung DR, Song JH, Kim SH, Thamlikitkul V, Huang SG, Wang $\mathrm{H}$, et al. High prevalence of multidrug-resistant nonfermenters in hospital-acquired pneumonia in Asia. Am J Respir Crit Care Med. 2011;184(12):1409-17. doi:10.1164/rccm.20110203490C

3. Antimicrobial Resistance Surveillance Program 2018 annual report. Muntinlupa, Philippines: Antimicrobial Resistance Surveillance Reference Laboratory, Research Institute for Tropical Medicine, Department of Health; 2019. Available from: https://arsp.com.ph/download/1041/, accessed 19 February 2021.

4. Hsu LY, Apisarnthanarak A, Khan E, Suwantarat N, Ghafur A, Tambyah PA. Carbapenem-resistant Acinetobacter baumannii and Enterobacteriaceae in South and Southeast Asia. Clin Microbiol Rev. 2017;30(1):1-22. doi:10.1128/CMR.masthead.30-1

5. Kiratisin P, Chongthaleong A, Tan TY, Lagamayo E, Roberts S, Garcia $\mathrm{J}$, et al. Comparative in vitro activity of carbapenems against major Gram-negative pathogens: results of Asia-Pacific surveillance from the COMPACT II study. Int J Antimicrob Agents. 2012;39(4):3116. doi:10.1016/j.ijantimicag.2012.01.002

6. Lee NY, Lee HC, Ko NY, Chang CM, Shih HI, Wu CJ, et al. Clinical and economic impact of multidrug resistance in nosocomial Acinetobacter baumannii bacteremia. Infect Control Hosp Epidemiol. 2007;28(6):713-9. doi:10.1086/517954

7. Kim DH, Choi JY, Kim HW, Kim SH, Chung DR, Peck KR, et al. Spread of carbapenem-resistant Acinetobacter baumannii global clone 2 in Asia and AbaR-type resistance islands. Antimicrob Agents Chemother. 2013;57(11):5239-46. doi:10.1128/AAC.00633-13

8. Ellington MJ, Ekelund O, Aarestrup FM, Canton R, Doumith M, Giske $\mathrm{C}$, et al. The role of whole genome sequencing in antimicrobial susceptibility testing of bacteria: report from the EUCAST Subcommittee. Clin Microbiol Infect. 2017;23(1):2-22. doi:10.1016/j. cmi.2016.11.012

9. Argimón S, Masim MAL, Gayeta JM, Lagrada ML, Macaranas PKV, Cohen $\mathrm{V}$, et al. Integrating whole-genome sequencing within the $\mathrm{Na}$ tional Antimicrobial Resistance Surveillance Program in the Philippines. Nat Commun. 2020;11(1):2719. doi:10.1038/s41467-020$16322-5$
10. M100S: performance standards for antimicrobial susceptibility testing, twenty-sixth edition. Wayne (PA): Clinical Laboratory Standards Institute; 2016.

11. Page AJ, De Silva N, Hunt M, Quail MA, Parkhill J, Harris SR, et al. Robust high-throughput prokaryote de novo assembly and improvement pipeline for Illumina data. Microb Genom. 2016;2(8):e000083. doi:10.1099/mgen.0.000083

12. Hunt M, Mather AE, Sanchez-Buso L, Page AJ, Parkhill J, Keane $J A$, et al. ARIBA: rapid antimicrobial resistance genotyping directIy from sequencing reads. Microb Genom. 2017;3(10):e000131. doi:10.1099/mgen.0.000131

13. Jolley KA, Bray JE, Maiden MCJ. Open-access bacterial population genomics: BIGSdb software, the PubMLST.org website and their applications. Wellcome Open Res. 2018;3:124. doi:10.12688/ wellcomeopenres.14826.1

14. Diancourt L, Passet V, Nemec A, Dijkshoorn L, Brisse S. The population structure of Acinetobacter baumannii: expanding multiresistant clones from an ancestral susceptible genetic pool. PLOS One. 2010;5(4):e10034. doi:10.1371/journal. pone.0010034

15. Gaiarsa S, Batisti Biffignandi G, Esposito EP, Castelli M, Jolley KA, Brisse S, et al. Comparative analysis of the two Acinetobacter baumannii multilocus sequence typing (MLST) schemes. Front Microbiol. 2019;10:930. doi:10.3389/fmicb.2019.00930

16. Higgins PG, Prior K, Harmsen D, Seifert H. Development and evaluation of a core genome multilocus typing scheme for wholegenome sequence-based typing of Acinetobacter baumannii. PLOS One. 2017;12(6):e0179228. doi:10.1371/journal. pone. 0179228

17. Tomaschek F, Higgins PG, Stefanik D, Wisplinghoff $H$, Seifert $H$. Head-to-head comparison of two multi-locus sequence typing (MLST) schemes for characterization of Acinetobacter baumannii outbreak and sporadic isolates. PLOS One. 2016;11(4):e0153014. doi:10.1371/journal.pone.0153014

18. Page AJ, Taylor B, Delaney AJ, Soares J, Seemann T, Keane JA, et al. SNP-sites: rapid efficient extraction of SNPs from multi-FASTA alignments. Microb Genom. 2016;2(4):e000056. doi:10.1099/ mgen.0.000056

19. Croucher NJ, Page AJ, Connor TR, Delaney AJ, Keane JA, Bentley $\mathrm{SD}$, et al. Rapid phylogenetic analysis of large samples of recombinant bacterial whole genome sequences using Gubbins. Nucleic Acids Res. 2015;43(3):e15. doi:10.1093/nar/gku1196

20. Stamatakis A. RAxML version 8: a tool for phylogenetic analysis and post-analysis of large phylogenies. Bioinformatics. 2014;30(9):1312-3. doi:10.1093/bioinformatics/btu033

21. Price MN, Dehal PS, Arkin AP. FastTree 2 - approximately maximum-likelihood trees for large alignments. PLOS One. 2010;5(3):e9490. doi:10.1371/journal.pone.0009490

22. David S, Reuter S, Harris SR, Glasner C, Feltwell T, Argimon S, et al. Epidemic of carbapenem-resistant Klebsiella pneumoniae in Europe is driven by nosocomial spread. Nat Microbiol. 2019;4(11):1919-29. doi:10.1038/s41564-019-0492-8

23. McArthur AG, Waglechner N, Nizam F, Yan A, Azad MA, Baylay $\mathrm{AJ}$, et al. The comprehensive antibiotic resistance database. Antimicrob Agents Chemother. 2013;57(7):3348-57. doi:10.1128/ AAC. $00419-13$

24. Hawkey J, Hamidian M, Wick RR, Edwards DJ, Billman-Jacobe $\mathrm{H}$, Hall RM, et al. ISMapper: identifying transposase insertion sites in bacterial genomes from short read sequence data. BMC Genomics. 2015;16:667. doi:10.1186/s12864-015-1860-2

25. Zarrilli R, Pournaras S, Giannouli M, Tsakris A. Global evolution of multidrug-resistant Acinetobacter baumannii clonal lineages. Int J Antimicrob Agents. 2013;41(1):11-9. doi:10.1016/j.ijantimicag.2012.09.008 
26. Mendes RE, Bell JM, Turnidge JD, Castanheira M, Jones RN. Emergence and widespread dissemination of OXA-23, -24/40 and -58 carbapenemases among Acinetobacter spp. in Asia-Pacific nations: report from the SENTRY Surveillance Program. J Antimicrob Chemother. 2009;63(1):55-9. doi:10.1093/jac/dkn434

27. García-Betancur JC, Appel TM, Esparza G, Gales AC, Levy-Hara G, Cornistein W, et al. Update on the epidemiology of carbapenemases in Latin America and the Caribbean. Expert Rev Anti Infect Ther. 2021;19(2):197-213. doi:10.1080/14787210.2020 .1813023

28. Tran DN, Tran HH, Matsui M, Suzuki M, Suzuki S, Shibayama K, et al. Emergence of New Delhi metallo-beta-lactamase 1 and other carbapenemase-producing Acinetobacter calcoaceticus-baumannii complex among patients in hospitals in $\mathrm{Ha}$ Noi, Viet Nam. Eur J Clin Microbiol Infect Dis. 2017;36(2):219-25. doi:10.1007/s10096016-2784-8

29. Wang J, Ning Y, Li S, Wang Y, Liang J, Jin C, et al. Multidrugresistant Acinetobacter baumannii strains with NDM-1: molecular characterization and in vitro efficacy of meropenem-based combinations. Exp Ther Med. 2019;18(4):2924-32. doi:10.3892/ etm.2019.7927

30. Xanthopoulou K, Urrutikoetxea-Gutierrez M, Vidal-Garcia M, Diaz de Tuesta Del Arco JL, Sanchez-Urtaza S, Wille J, et al. First report of New Delhi metallo-beta-lactamase-6 (NDM6) in a clinical Acinetobacter baumannii isolate From northern Spain. Front Microbiol. 2020;11:589253. doi:10.3389/ fmicb. 2020.589253

31. Heritier C, Poirel L, Nordmann P. Cephalosporinase over-expression resulting from insertion of ISAbal in Acinetobacter baumannii. Clin Microbiol Infect. 2006;12(2):123-30. doi:10.1111/j.14690691.2005.01320.x

32. Higgins PG, Dammhayn C, Hackel M, Seifert H. Global spread of carbapenem-resistant Acinetobacter baumannii. J Antimicrob Chemother. 2010;65(2):233-8. doi:10.1093/jac/dkp428
33. Levin AS, Gobara S, Mendes CM, Cursino MR, Sinto S. Environmental contamination by multidrug-resistant Acinetobacter baumannii in an intensive care unit. Infect Control Hosp Epidemiol. 2001;22(11):717-20. doi:10.1086/501852

34. Thom KA, Johnson JK, Lee MS, Harris AD. Environmental contamination because of multidrug-resistant Acinetobacter baumannii surrounding colonized or infected patients. Am J Infect Control. 2011;39(9):711-5. doi:10.1016/j.ajic.2010.09.005

35. Lopes BS, Al-Agamy MH, Ismail MA, Shibl AM, Al-Qahtani AA, Al-Ahdal MN, et al. The transferability of bla $0 \times A-23$ gene in multidrugresistant Acinetobacter baumannii isolates from Saudi Arabia and Egypt. Int J Med Microbiol. 2015;305(6):581-8. doi:10.1016/j. ijmm.2015.07.007

36. Makke G, Bitar I, Salloum T, Panossian B, Alousi S, Arabaghian $\mathrm{H}$, et al. Whole-genome-sequence-based characterization of extensively drug-resistant Acinetobacter baumannii hospital outbreak. mSphere. 2020;5(1):e00934-19. doi:10.1128/ mSphere.00934-19

37. Qu J, Du Y, Yu R, Lu X. The first outbreak caused by Acinetobacter baumannii ST208 and ST195 in China. Biomed Res Int. 2016;2016:9254907. doi:10.1155/2016/9254907

38. Feng Y, Ruan Z, Shu J, Chen CL, Chiu CH. A glimpse into evolution and dissemination of multidrug-resistant Acinetobacter baumannii isolates in East Asia: a comparative genomics study. Sci Rep. 2016;6:24342. doi:10.1038/srep24342

39. Fitzpatrick MA, Ozer EA, Hauser AR. Utility of whole-genome sequencing in characterizing Acinetobacter epidemiology and analyzing hospital outbreaks. J Clin Microbiol. 2016;54(3):593-612. doi:10.1128/JCM.01818-15

40. Gramatniece A, Silamikelis I, Zahare I, Urtans V, Zahare I, Dimina E, et al. Control of Acinetobacter baumannii outbreak in the neonatal intensive care unit in Latvia: whole-genome sequencing powered investigation and closure of the ward. Antimicrob Resist Infect Control. 2019;8:84. doi:10.1186/s13756-019-0537-z 